\title{
PENILAIAN VALUE AT RISK DENGAN PENDEKATAN \\ EXTREME VALUE THEORYDAN GENERALIZED PARETO DISTRIBUTION STUDI KASUS BANK BUMN DI INDONESIA PADA PERIODE TAHUN 2008-2018
}

\author{
YanurAkhmadi \\ Iqbal Musthofa \\ Hotmauly Media Rika \\ Dewi Hanggraeni \\ Fakultas Ekonomi dan Bisnis, Universitas Indonesia \\ yanursukses09@gmail.com
}

\begin{abstract}
Abstrak
Perkembangan sektor perbankan di Indonesia dalam 10 tahun mengalami pertumbuhan yang agresif, tetapi juga memperhatikan rasio modal berdasarkan risiko sesuai dengan ketentuan otoritas. Bank BUMN di Indonesia menguasasi $\pm 45 \%$ dari total aset pada sektor perbankan, dan memiliki rasio penyediaan modal minimum yang lebih tinggi dari yang disyaratkan otoritas. Penelitian in imembahas perhitungan VaR dengan metode GEV dan GPD, serta membandingkannya dengan rasio penyediaan modal minimum bank. Hasil perhitungan dengan menggunakan metode GPD paling mendekati nilai rasio modal bank, selain itu kedua hasil perhitungan baik GEV dan GPD lebih tinggi saat dibandingkan dengan perhitungan VaR dengan metode lainnya ataupun ketentuan yang ditetapkan oleh otoritas.
\end{abstract}

Keyword: Capital Adequacy, Extreme Value Theory, GEV, GPD, VaR.

\section{PENDAHULUAN}

Pasca krisis yang terjadi di tahun 2008, sektor perbankan Indonesia terus mengalami pertumbuhan yang cukup signifikan. Berdasarkan Statistik Perbankan Indonesia (BI \& OJK), total aset bank umum per Desember 2008 sebesar IDR 2.310.557 Miliar menjadi sebesar IDR 8,068,346 Miliar per Desember 2018, peningkatan juga terlihat dari indikator penyaluran dana maupun sumber dana yang dihimpun oleh bank umum. Melihat dari sisi kecukupan modal, rasio kecukupan modal perbankan di Indonesia juga mengalami perbaikan yang signifikan, yaitu dari 16.76\% pada akhir 2008 menjadi $22,97 \%$ pada akhir 2018. Berlawanan dengan rasio modal, rasio pinjaman terhadap dana (LDR) mengalami peningkatan dari angka 74,58\% pada akhir 2018 menjadi 94,78\%. Hal ini mengindikasikan dalam 10 tahun terkahir bank agresif dalam menyalurkan pinjaman, namun tetap menjaga rasio modal pada angka yang memadai.

Melihat bank umum di Indonesia, 45\% aset bank umum dimiliki oleh 4 bank BUMN, yaitu BRI, Mandiri, BNI, dan BTN. Dominasi bank BUMN pada sektor perbankan 
di Indonesia, juga dapat dilihat secara umum dari jumlah bank BUMN yang termasuk dalam kelas bank BUKU IV, dimana 3 dari 5 bank yang termasuk dalam kelas ini merupakan bank BUMN.

Per tahun 2009, seluruh bank BUMN sudah melakukan Initian Public Offering (IPO) dan tercatat pada Bursa Efek Indonesia (BEI), diawali oleh BNI pada 1996 yang kemudian diikuti oleh BRI dan Mandiri pada 2003, kemudian BTN pada 2009. Saat dibandingkan dengan data indeks JKFINA, indeks sektoral pada BEI untuk sektor keuangan, volatilitas saham bank BUMN cenderung lebih tinggi dibandingkan dengan volatilitas indeks yang mencerminkan volatilitas sektoral. Hal ini disimpulkan dari nilai standar deviasi yang lebih tinggi pada data bank BUMN dibandingkan dengan data indeks. Volatilitas ini tentunya mempengaruhi perhitungan Value at Risk (VaR) suatu bank yang akan mempengaruhi pula kecukupan modal atas bank tersebut.

Penelitian ini akan membahas perhitungan VaR pada bank BUMN di Indonesia menggunakan dua pendekatan berbeda, yaitu Generalized Extreme Value (GEV) dan Generalized Pareto Distribution (GPD), serta menentukan pendekatan mana yang lebih baik dalam menentukan kecukupan modal suatu bank.

\section{TINJAUAN PUSTAKA}

Menurut Veithzal (2013), risiko pasar merupakan risiko yang timbul karena adanya pergerakan pada variabel pasar dari portofolio yang dimiliki oleh bank, yang dapat merugikan bank (adverse moment). Risiko tersebut dapat dikatakan sebagai fluktuasi pasar dimana secara keseluruhan bisa mempengaruhi variabilitas return dari investasi. Risiko pasar menurut Salinan Surat Edaran Otoritas Jasa Keuangan Nomor 35/SEOJK.03/2015 Tentang Perhitungan Aset Tertimbang Menurut Risiko dengan menggunakan metode standar bagi bank umum konvensional. Risiko pasar dalam perhitungan KPMM mencakup risiko benchmark suku bunga, risiko nilai tukar, risiko ekuitas, dan/atau risiko komoditas.

Risiko pasar pada pasar keuangan tercermin pada harga saham, dengan asumsi bahwa investor telah mengetahui seluruh risiko yang ada. Investor akan membandingkan nilai instrinsik suatu saham dengan harga pasarnya untuk dalam penentuan keputusan investasi (Halim, 2005). Metode yang digunakan dalam pengukuran risiko pasar adalah Value at Risk (VaR). Model ini diperkenalkan oleh Bank of International Settlement (BIS) untuk mengukur risiko pasar baik bagi perbankan maupun perusahaan diluar perbankan.

Menurut Jorion (2002), Value at Risk adalah suatu metode pengukuran risiko yang mengukur estimasi kerugian maksimum yang mungkin terjadi pada suatu posisi portfolio sebagai akibat perubahan faktor-faktor risiko pada periode tertentu dalam kondisi pasar normal dan pada tingkat kepercayaan tertentu. Perhitungan VaR yang dilakukan tergantung pada periode waktu yang telah ditetapkan dalam kondisi pasar 
yang normal VaR merupakan metode yang paling sering digunakan dalam mengukur risiko di pasar finansial terutama pada institusi keuangan yang tunduk pada peraturan Basel Capital Accord, dalam hal ini adalah industri keuangan perbankan.

Kelebihan utama perhitungan VaR adalah metode ini dapat diterapkan pada seluruh instrumen trading (Best, 1998), seperti kurs, tingkat bunga, komoditas dan harga saham, termasuk juga indeks pasar saham. Disisi lain, menurut Butler (1999), VaR dapat memberikan beberapa kontribusi bagi manajemen risiko, yaitu membantu efisiensi dalam pengalokasian sumber daya untuk menghindari overexpsed pada suatu sumber risiko, dengan menggunakan perhitungan ini, maka regulator dapat menerapkan penilaian kecukupan modal pada suatu lembaga keuangan berdasarkan tingkat risikonya.

Pendekatan VaR digunakan untuk menghitung kerugian terburuk dalam satu periode pada kemungkinan yang telah ditentukan saat kondisi pasar sedang normal.Namun pendekatan ini telah banyak mendapat kritikan (Faishal, 2010), karena pada perhitungan dengan metode parametrik umumnya menggunakan distribusi normal. Kenyataannya kondisi tidak selalu normal, seperti yang terjadi pada tahun 2008, Indonesia mengalami krisis keuangan. Dengan menggunakan model perhitungan VaR, tidak dapat menangkap risiko pada quantile yang tinggi (fat-tailed series), dimana kondisi tersebut banyak ditemukan pada data-data keuangan.

Banyak penelitian yang telah menggunakan Extreme Value Theory (EVT) untuk mengukur risiko penurunan pasar konvensional terutama pada kejadian ekstrim dengan data yang berekor gemuk dan tidak dapat menggunakan model pendekatan tradisional. EVT menjadi populer karena kemampuannya dalam memprediksi peristiwa ekstrim (Dacorogna et al., 1995). Mc Neil dan Frey (2000) menggunakan model GARCH untuk mencerminkan volatilitas dalam estimasi risiko dan menemukan hasil yang terbaik untuk mendukung teori nilai ekstrim.

Studi lain yang menggunakan estimasi risiko berbasis EVT antara lain Gencay dan Selcuk (2004), Longin (2005), Rocco (2009), yang menganalisa kinerja relatif dari model risiko pasar untuk daily stock return dari pasar saham dinegara berkembang. Hasil mereka menunjukkan bahwa estimasi risiko berbasis model EVT lebih akurat pada quantile yang lebih tinggi.

Model EVT dapat dihitung dengan dua metode, yaitu metode Block Maxima atau dikenal dengan model Generalized Extreme Value (GEV) dan metode Peaks Over Threshold atau dikenal dengan model Generalized Pareto Distribution (GPD). Beberapa penelitian mengenai extreme value theory menggunakan model GPD antara lain Gencay dan Selcuk (2002), Malevergne, Y. Et all., (2006), Maghyereh dan Al-Zoubi (2006). Sedangkan beberapa peneliti menggunakan model GEV, diantaranya Bensalah (2000), Markose dan Alentorn (2011).Pada penelitian Ambasari (2016), perhitungan VaR dengan model GPD menghasilkan nilai yang lebih besar dibandingkan VaR dengan model GEV. Hasil dari penelitian Mwamba, Hammoudeh dan Gupta (2014) 
menemukan bahwa dengan menggunakan kedua model (GEV dan GPD) ketika kondisi pasar volatile maka akan memberikan dampak negatif pada portofolio, tetapi pada indeks saham syariah memiliki risiko yang lebih rendah terutama saat krisis.

\section{Gambar 1}

Kerangka Konseptual

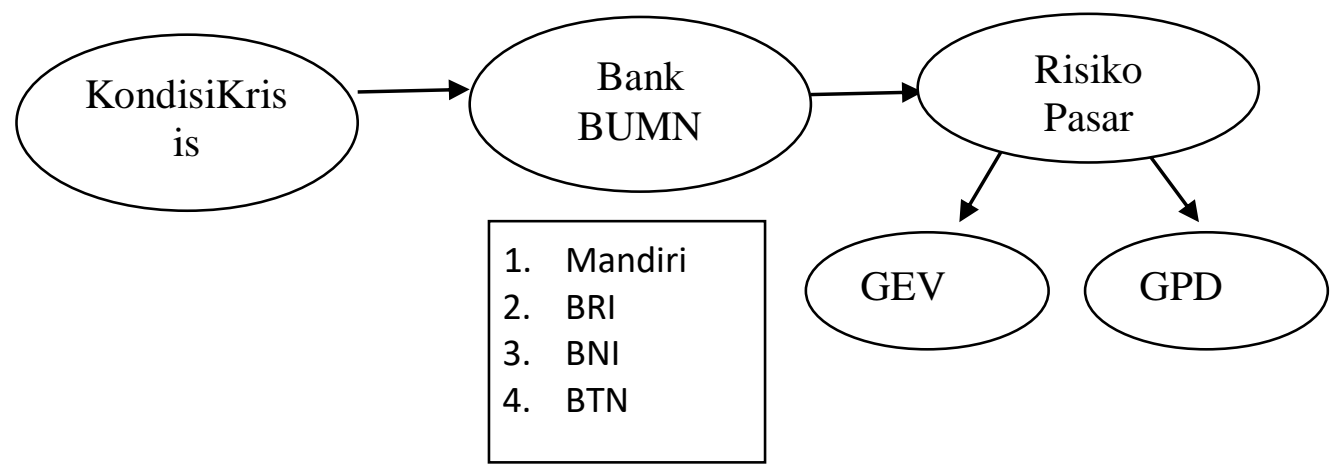

\section{METODE PENELITIAN}

Jenis data yang digunakan adalah data sekunder berupa data deret waktu (time series) dari tahun 2008-2018. Penelitian ini menggunakan data tahun 2008 untuk melihat tingkat risiko perbankan pasca krisis. Data menggunakan harga saham bank BUMN yang ada di Indonesia, yaitu Bank Negara Indonesia (BNI), Bank Rakyat Indonesia (BRI), Bank Tabungan Negara dan Bank Mandiri, karena telah mewakili 45\% dari seluruh total aset di sektor perbankan. Data dikumpulkan dalam bentuk data harian harga saham yang diperoleh dari situs yahoofinance.com, pengolahan data indeks saham perbankan (JKFINA), serta laporan keuangan bank dari situs bursa efek Indonesia. Penelitian ini menggunakan Oxmetrics6 dalam pengolahan data.

\section{Metode Block-Maxima}

Metode ini, membagi risiko dalam bentuk blok-blok pada periode waktu tertentu, misalnya bulanan, triwulanan, semesteran, atau tahunan. Untuk setiap blok periode ditentukan besarnya risiko yang tertinggi pada periode blok tersebut, sehingga diperoleh nilai risiko maksimal masing-masing blok periode. Metode Block-Maxima diperkirakan akan mengikuti distribusi Generalized Extreme Value (GEV) dalam Teori Fisher dan Tippet (1928), lalu dikembangkan oleh Gnedenko (1943) dengan rumus cdf sebagai berikut:

$$
f(x)=\exp \left\{-\left[1+\xi\left(\frac{\mathrm{x}-\mu}{\sigma}\right)\right]^{-\frac{1}{\xi}}\right\} j i k a \xi \neq 0, \xi\left(\frac{\mathrm{x}-\mu}{\sigma}\right)>0
$$




$$
f(x)=\exp -\left[\exp -\left(\frac{\mathrm{x}-\mu}{\sigma}\right)\right] j i k a \xi=0
$$

Dimana : $\xi$ adalah parameter shape/tail index, oadalah scale dan $\mu$ adalah parameter location

\section{Metode Peaks Over Threshold}

Pada metode Peaks Over Threshold (POT), menentukan kerugian maksimum menggunakan nilai ambang yang disebut threshold. Pemilihan nilai threshold dilakukan pada data yang berada diatas nilai threshold, nilai tersebut merupakan $10 \%$ dari keseluruhan data yang telah diurutkan dari yang terbesar hingga terkecil. Nilai threshold merupakan data urutan ke, dimana merupakan banyaknya nilai ekstrim. Metode ini diperkirakan mengikuti Generalized Pareto Distribution (GPD) dalam Teori Pickland, Dalkema dan de Hann (1975). Secara umum GPD dapat dirumuskan sebagai berikut:

$$
V a R=\mu+\frac{\Psi}{\xi}\left\{\left[\frac{n}{M} 1-p\right]^{-\xi}-1\right\}
$$

Dimana $: \mu$ adalah parameter location, $\xi$ adalah parameter shape/tail index, $\Psi$ adalah scale, $\mathrm{n}$ adalah total jumlah data observasi dan $\mathrm{M}$ adalah jumlah data di atas threshold

\section{HASIL DAN PEMBAHASAN}

\section{Statistik Deskriptif Harga Saham}

Pada Tabel 1, perhitungan standar deviasi untuk keempat saham yang diteliti menunjukkan tingkat volatilitas yang cenderung serupa, dengan hasil tertinggi pada BBRI dan terendah pada BBTN. Angka mean, skewness, kurtosis, serta Jarque-Bera dihitung untuk mendapatkan gambaran atas data yang digunakan dalam penelitian.

Tabel 1

StatitikDeskriptif

\begin{tabular}{ccccc}
\hline & BBNI & BBRI & BBTN & BMRI \\
\hline Mean & 0.00101 & 0.00091 & 0.00089 & 0.00105 \\
\hline Std Dev & 0.02521 & 0.02546 & 0.02443 & 0.02461 \\
\hline Skewness & 0.34798 & 0.55390 & 0.22153 & 0.69546 \\
\hline Kurtosis & 11.61000 & 5.36540 & 5.84330 & 7.01120 \\
\hline JB & 15298 & 3394 & 2206 & 5778 \\
\hline
\end{tabular}

Sumber : Hasil olah data

Dapatdilihat pada tabel diatas bahwa nilai skewness bank BNI, BRI, BTN dan Mandiri memiliki nilai $>0$ dan nilai kurtosis $>3$. Hal ini membuktikan pada penelitian ini data yang digunakan tidak terdistribusi normal (Sheskin, 2011). Keempat data bank tersebut memiliki kemiringan skewness positif dan leptokurtic (ramping keatas). Maka dapat 
disimpulkan bahwa dengan menggunakan model Extreme Value Theory untuk menghitung nilai VaR dalam penelitian ini adalah model yang terbaik.

\section{Rasio Kecukupan Modal Bank}

Per Desember 2018, data pada laporan keuangan tahunan seluruh bank BUMN di Indonesia menunjukkan rasio kecukupan modal yang melebihi batas yang ditentukan oleh OJK, yaitu minimal 9\% berdasarkan POJK No. 11/POJK.03/2016. Angka rasio penyediaan modal minimum diatas merupakan rasio untuk risiko kredit, opersional, dan pasar.Bank diharuskan untuk menghitung Asset Tertimbang Menurut Risiko (ATMR) berdasarkan 3 risiko yang telah disebutkan sebelumnya, berdasarkan POJK No. 11 tahun 2016.

Tabel 2

RasioPenyediaan Modal Minimum per 31 Desember 2018

\begin{tabular}{lcccc}
\hline & BBNI & BBRI & BBTN & BMRI \\
\hline $\begin{array}{l}\text { RasioPenyediaan } \\
\text { Modal Minimum }\end{array}$ & $18.50 \%$ & $21.21 \%$ & $18.21 \%$ & $20.96 \%$ \\
\hline
\end{tabular}

Sumber : Hasil olah data

Modal tertinggi dimiliki oleh BBRI, yaitu sebesar $21.21 \%$ dari ATMR bank tersebut. Diikuti oleh BMRI, BBNI, dan BBTN secara berurutan.Kecukupan modal yang cukup jauh diambang batas yang ditentukan oleh OJK mengindikasikan bahwa keempat bank BUMN dapat menanggung risiko atas setiap aktifa produktif berisiko yang dimiliki bank.

Membandingkan rasio penyediaan modal minimum pada Tabel 2 dengan hasil perhitungan Value at Risk (VaR) dibawah, seluruh rasio pada bank BUMN melebihi nilai VaR yang dihasilkan, baik pada tingkat signifikansi $5 \%$ ataupun $1 \%$. Hal ini mengindikasikan hal yang sama, dimana bank dapat menanggung risiko yang lebih besar, melebihi estimasi kerugian terburuk yang mungkin dihadapi oleh bank. Jorion (2007) mendefinisikan VaR sebagai estimasi kerugian terburuk selama jangka waktu tertentu pada tingkat kepercayaan tertentu yang telah ditentukan.

Tabel 3

Hasil PerhitunganVaR

\begin{tabular}{rrrrrr}
\hline \multicolumn{1}{r}{ VaR } & & BBNI & BBRI & BBTN & BMRI \\
\hline 0.95 & $5.71 \%$ & $5.80 \%$ & $5.91 \%$ & $5.50 \%$ \\
\hline 0.99 & $7.86 \%$ & $6.85 \%$ & $7.36 \%$ & $7.28 \%$ \\
\hline
\end{tabular}

Sumber : Hasil olah data 


\section{PerhitunganVaR: GEV dan GPD}

Perhitungan VaR dengan mengunakan metode GEV dan GPD atas data bank BUMN dalam penelitian ini menunjukkan angka yang lebih tinggi dibandingkan dengan hasil perhitungan VaR yang umum digunakan. Fokus GEV/GPD pada perilaku daerah ekor (tail) atas suatu distribusi serta peristiwa yang berkarakteristik low frequency high impact kemungkinan menjadikan nilai VaR yang dihasilkan lebih besar saat metode ini digunakan (Gencay dan Selcuk, 2004), (Longin, 2005), (Rocco, 2009).

Perhitungan VaR menggunakan GEV baik pada tingkat signifikansi $5 \%$ ataupun $1 \%$, lebih besar dibandingkan dengan perhitungan $\mathrm{VaR}$ umum, serta lebih kecil dibandingkan dengan rasio penyediaan modal minimum bank. Perhitungan dengan menggunakan metode GPD tetap lebih besar saat dibandingkan dengan hasil perhitungan VaR umum (Ambasari, 2016).Namun saat dibandingkan dengan rasio penyediaan modal minimum, terdapat hasil perhitungan VaR yang lebih besar. Hasil perhitungan GPD mengindikasikan adanya kekurangan modal pada salah satu bank yang menjadi objek penelitian, yaitu BBNI.

Tabel 4

VaR, GEV, GPD, Rasio Modal Minimum

\begin{tabular}{cccccc}
\hline & \multicolumn{2}{c}{ BBNI } & BBRI & BBTN & BMRI \\
\hline VaR & & & & & \\
\hline & 0.95 & $5.71 \%$ & $5.80 \%$ & $5.91 \%$ & $5.50 \%$ \\
\hline GEV & 0.99 & $7.86 \%$ & $6.85 \%$ & $7.36 \%$ & $7.28 \%$ \\
\hline & & & & & $11.08 \%$ \\
\hline GPD & 0.95 & $11.09 \%$ & $12.43 \%$ & $11.00 \%$ & $12.23 \%$ \\
\hline & 0.99 & $13.16 \%$ & $13.54 \%$ & $11.57 \%$ & $20.00 \%$ \\
\hline & 0.95 & $20.00 \%$ & $18.97 \%$ & $12.61 \%$ & $20.00 \%$ \\
\hline $\begin{array}{c}\text { Rasio Penyediaan Modal Minimum } \\
\text { per Des 2018 }\end{array}$ & 0.99 & $20.00 \%$ & $18.97 \%$ & $13.61 \%$ & $20.96 \%$ \\
\hline Rasio Modal Minimum BI & $18.50 \%$ & $21.21 \%$ & $18.21 \%$ & \\
\hline
\end{tabular}

Sumber : Hasil olah data

Tabel 4 juga menunjukkan bahwa perhitungan $\mathrm{VaR}$ dengan menggunakan metode GPD merupakan perhitungan yang menghasilkan nilai yang paling mendekati rasio penyediaan modal minimum pada bank BUMN di Indonesia.

\section{KESIMPULAN}

Dalam penelitian ini, penggunaan model Extreme Value Theory adalah pengukuran model terbaik untuk mengestimasi nilai VaR (Gencay dan Selcuk, 2004), (Longin, 2005), (Rocco, 2009), hal ini disebabkan oleh data keuangan saham bank BNI, BRI, BTN dan Mandiri tidak terdistribusi normal. 
Membandingkan metode GEV dengan GPD dalam menghitung VaR, disimpulkan bahwa dengan menggunakan metode GPD menghasilkan nilai VaR yang lebih tinggi (Ambasari, 2016), sehingga jika menentukan standar rasio penyediaan modal minimum pada bank BUMN di Indonesia membutuhkan cadangan modal yang lebih besar. Hasil perhitungan menggunakan metode GPD paling mendekati nilai rasio modal yang saat ini dimiliki oleh bank sehingga dapat disimpulkan bahwa cadangan modal bank telah cukup dapat menyerap potensi kerugian yang dapat disebabkan oleh risiko pasar.

\section{IMPLIKASI}

Penelitian tentang cadangan modal bank berdasarkan risiko pasar menggunakan Extreme Value Theory belum ada di Indonesia, sehingga penelitian ini dapat menjadi salah satu referensi dalam perbandingan pengukuran risiko pasar menggunakan EVT khususnya pada kedua model yaitu GEV dan GPD.

\section{KETERBATASAN DAN SARAN}

Adapun keterbatasan dalam penilitian ini ialah pada data yang digunakan, dimana peneliti hanya mengunakan data empat bank dari seluruh 124 bank umum yang berada di Indonesia. Peneliti juga hanya berfokus pada bank umum konvensional tanpa menggunakan data bank umum syariah. Selain itu, risiko konglomerasi juga tidak dipertimbangkan dalam penelitian ini, dimana berdasarkan SEOJK No.14 tahun 2015 bank wajib untuk menerapkan manajemen risiko terintigrasi bagi konglomerasi keuangan.

Saran untuk penelitian selanjutnya ialah penelitian dengan menggunakan data yang lebih besar, serta mempertimbangkan risiko konglomerasi serta risiko lainnya yang dapat mempengaruhi tingkat risiko bank.

\section{DAFTAR PUSTAKA}

Ambasari, A, Sudarno, T. 2016. Perbandingan Pendekatan Generalized Extreme Value dan Generalozed Pareto Distribution Untuk Perhitungan Value at Risk Pada Portofolio Saham. Jurnal Gaussian Vol 5, Nomor 3:361-371.

Bensalah, Younes. 2000. Steps in Applying Extreme Value Theory to Finance. Bank of Canada Working Paper.

Best, Philip. 1998. Implementing Value at Risk. England : John Wiley \& Sons, Ltd

Butler, Cormac. 1999. Mastering Value at Risk.A step-by-step Guide to Understanding and Applying VaR. England : Prentice Hall

Dacorogna, M. M., MÄuller, U. A., Pictet, O. V., and de Vries, C. G. (1995). The Distribution of Extremal Foreign Exchange Rate Returns in Extremely Large Data Sets. Preprint, O\&A Research Group. 
Gencay, R., Selcuk, F., and UlugÄulya.gci, A. (2002). Extreme Value Theory and Value at Risk

:Relative Performance in Emerging Market.Financial Valuation and Risk Management Working Paper.

Faishal, Ahmad. 2010. Pengukuran Market Risk Untuk Investasi PT Bakrie \& Brothers, Tbk Pada Saham PT Bumi Resources Indonesia Dengan Model Extreme Value Theory

Fisher, R. A. and Tippett, L. H. C. (1928).Limiting Forms of The Frequency Distribution of The Largest or Smallest Member of A Sample. Proceeding of Cambridge Philosophical Society, 24, 180-190.

Gencay, R., Selcuk, F., and UlugÄulya.gci, A. 2003a.EVIM: A Software Package for Extreme Value Analysis in Matlab. Studies in Nonlinear Dynamics andEconometrics, 5:213-239.

Gencay, R., Selcuk, F., and UlugÄulya.gci, A. 2003b.High Volatility, Thick Tails and Extreme Value Theory in Value-at-Risk Estimation.Insurance: Mathemat-ics and Economics, 33:337-356.

Gilli, M., and Kellezi, E. 2006.An Application of Extreme Value Theory for Measuring Financial Risk. Article Published in Computational Economics 27(1), 1-23.

Halim, Abdul. 2005. Analisis Investasi, Penerbit Salemba Empat, Jakarta.

Jorion, P. 2002.Value at Risk: A New Brenchmark for managing Financial Risk. Singapore :

McGraw Hill.

Jorion, P. 2007. Value at Risk: The New Benchmark for Managing Financial Risk Third Edition.

New York: The McGraw-Hill Companies, Inc.Longin, F. M. 1996.The Assymptotic Distribution of Extreme Stock Market Returns.Journal of Business, 69:383-408.

Longin, F. 2005.The Choice of The Distribution of Asset Returns: How Extreme Value Theory Can Help? Journal of Banking \& Finance, Elsevier, 29(4), 1017-1035.

Malevergne,Y., et al. 2006. Applied Financial Economics on The Power of Generalized Extreme Value and Generalized Pareto Distribution Estimators for Empirical Distributions of Stock Returns.

Maghyereh, A.I., dan Al-Zoubi H.A. 2006. Value at Risk Under Extreme Values: The Relative Performance in MENA Emerging Markets. International Journal of Managerial Finance.

McNeil, A. J. 1999. Extreme Value Theory for Risk Managers. In Internal Modelling and CAD II, pages 93-113. RISK Books.

McNeil, A. J. and Frey, R. 2000.Estimation of Tail-related Risk Measures for Heteroscedastic Financial Time Series: An Extreme Value Approach.Journal ofEmpirical Finance, 7 (3\&4) :271-300. 
Ototritas Jasa Keuangan. 2016. POJK No. 11/POJK.03/2016 Tentang Kewajiban Penyediaan Modal Minimum Bank Umum. Jakarta.

Pickands, J. (1975). Statistical Inference Using Extreme Order Statistics. Annals of Statistics, 3, 119-131.

Rocco, M. 2011. Extreme Value Theory for Finance: A Survey. Bank of Canada. https://ideas.repec.org/p/bdi/opques/qef_99_11.html

Sheskin DJ. 2011. Handbook of Parametric and Nonparametric Statistical Procedures. $5^{\text {th }}$ ed. Boca Raton: Chapman \& Hall /CRC.

Surat Edaran Otoritas Jasa Keuangan Nomor 35/SEOJK.03/2015 Tentang Perhitungan Aset Tertimbang Menurut Risiko

Veithzal, Rivai,dkk.2013.Commercial Bank Management.Jakarta: Rajawali Pers. Westfall PH 2014 Kurtosis as Peakedness, 1905 - 2014. R.I.P.The American Statistician 68:191-195

- - 2000. "Nonparametric Risk Management and Implied Risk Aversion." Journal of Econometrics, 94, pp. 9-51. 